\section{Smoking gun}

During the first half of the twentieth century, consumption of manufactured cigarettes increased greatly in the Western world. A rapid increase in lung cancer in men was also evident, and the prevailing view was that this was a result of improved diagnosis, although there was also discussion about the role of increased air pollution or cigarette smoking. More than anyone else, the research of the British epidemiologists Richard Doll and Tony Bradford Hill was responsible for the now widely accepted view that most lung cancers are caused by cigarette smoking.

In 1939, a German study indicated that non-smokers were more common in healthy populations than among lung cancer patients. There followed reports of several case-control studies associating lung cancer with cigarette smoking, including a study in early 1950 from researchers in the USA, Ernst Wynder and Evarts Graham. This study involved over 600 lung cancer cases and 600 controls. Six months later, Doll and Hill reported a larger casecontrol study in the British Medical Journal, and concluded that smoking was "a cause, and an important cause" of lung cancer.

The real milestone came when Doll and Hill designed a prospective cohort study to overcome concerns regarding bias. They sent out questionnaires to more than 34,000 male British physicians to collect details of their smoking habits, which were followed up with further questionnaires, and recorded the causes of death. The first report of this study was published in the British Medical Journal in 1954, with a follow-up report in 1956. Their earlier case-control findings were confirmed. They showed a higher mortality in smokers than in non-smokers, and a clear dose-response relationship between the amount smoked and

"This was, I believe, the first unequivocally-established cause of cancer that affected large proportions of the general population." Laurence N. Kolonel

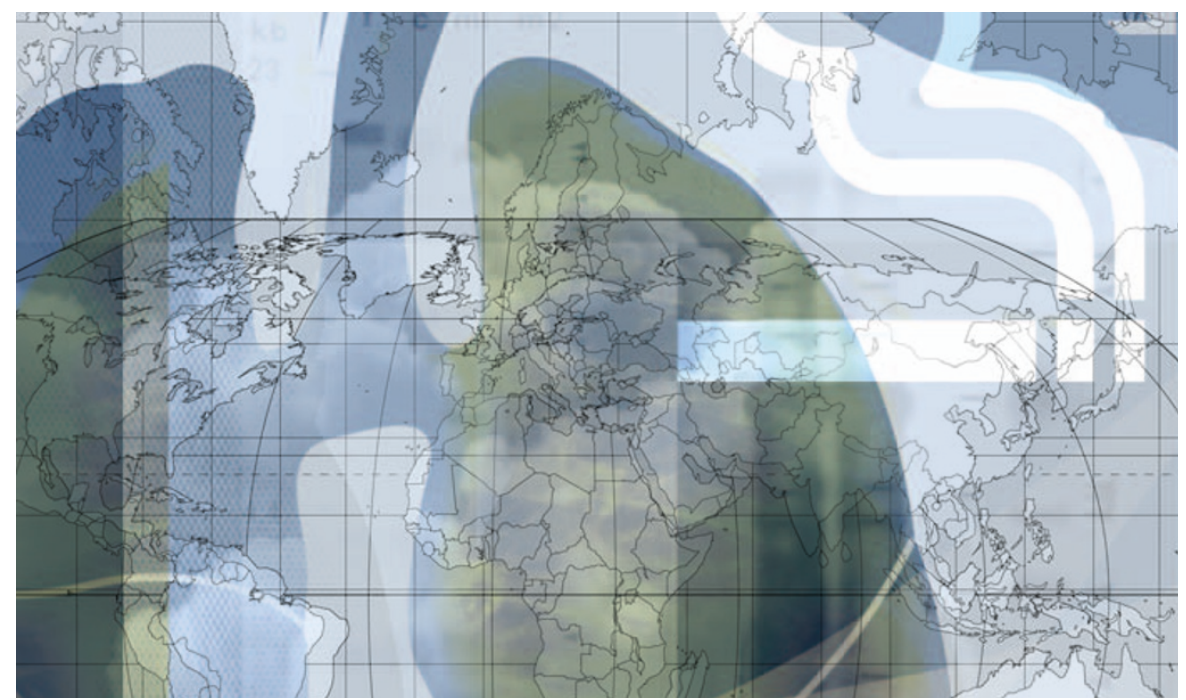

the death rate from lung cancer. The data also indicated a progressive and significant reduction in mortality with the increase in the length of time over which smoking had been given up. There was remarkably little difference between the smoking habits of doctors who lived in large towns and those who lived in other districts, so the authors concluded that lung cancer could not be attributed to a differential exposure to atmospheric pollution.

These reports, along with other cohort studies published in the 1950s, formed the basis for the 1964 report of the United States Surgeon General, which concluded that "Cigarette smoking is causally related to lung cancer in men; the magnitude of the effect of cigarette smoking far outweighs all other factors."

The Doll and Hill study is unique in its regular updating of the smoking habits of the participants. The latest (and final) 50-year follow-up report was published in 2004 by Doll and colleagues, including Richard Peto, a 30-year collaborator on the study. The results showed that among men born between 1910 and 1930, prolonged cigarette smoking caused death to occur on average 10 years earlier than that of lifelong non-smokers, but cessation at age 50 halved the hazard and cessation at age 30 almost eliminated it.

Despite these indisputable data, and consequent findings identifying the carcinogens in tobacco and establishing the mechanisms of carcinogenesis, about 1 billion men worldwide are daily smokers and smoking still causes about 1.2 million deaths worldwide annually.

\section{Ezzie Hutchinson, Chief Editor,}

Nature Reviews Cancer

\section{References and Links}

ORIGINAL RESEARCH PAPERS Wynder, E. L. \& Graham, E. A. Tobacco smoking as a possible etiologic factor in bronchiogenic carcinoma. JAMA 143, 329-336 (1950) | Doll, R. \& Hill, A. B. Smoking and carcinoma of the lung: preliminary report. $B M J$ 221, 739-748 (1950) | Doll, R. \& Hill, A. B. The mortality of doctors in relation to their smoking habits: a preliminary report. BMJ 228, 1451-1455 (1954) | Doll, R. \& Hill, A. B. Lung cancer and other causes of death in relation to smoking: a second report on the mortality of British doctors. BMJ $\mathbf{2 3 3}$ 1071-1076 (1956)

FURTHER READING Müller, F. H. Tabakmissbrauch und lungencarcinoma. Z. Krebsforsch. 49, 57-85 (1939) | United States Public Health Service. Smoking and Health. Report of the Advisory Committee to the Surgeon General of the Public Health Service (United States Department of Health, Education, and Welfare, Public Health Service, Center for Disease Control, Washington DC, 1964) <http://www.cdc.gov/tobacco/sgr/sgr_ 1964/sgr64.htm> | Doll, R., Peto, R., Boreham, J. \& Sutherland, I. Mortality in relation to smoking: 50 years' observations on male British doctors. BMJ 328, 1519-1528 (2004) | Hecht, S. Tobacco carcinogens, their biomarkers and tobacco-induced cancer. Nature Rev. Cancer 3, 733-744 (2003)
URL

lung cancer

http://www.cancer.gov/cancertopics/types/lung 